\title{
Using Humorous Texts in Improving Reading Comprehension of EFL Learners
}

\author{
A. Majid Hayati \\ Shahid Chamran University, Iran \\ Email: majid_hayati@yahoo.com \\ Zohreh Gooniband Shooshtari \\ Shahid Chamran University, Iran \\ Email: zshooshtari@yahoo.com \\ Nahid Shakeri \\ Shahid Chamran University, Iran \\ Email: shakerinahid87@yahoo.com
}

\begin{abstract}
The present paper investigates the effect(s) of humorous texts on reading comprehension of EFL students. For this purpose, forty students, randomly divided into two groups $(n=20)$, were invited to attend the reading sessions. The humorous group comprised the participants who read the reading texts preceded by a joke, and the non-humorous group consisted of students who studied the same reading text without a joke. The findings with respect to the t-test which compared the scores of recall tests of both groups over the seven sessions revealed no significant difference between the recall performances of the two groups. However, comparing the scores obtained from the first and the last reading by humorous group showed a significant improvement in the recall and comprehension of the experimental group. The findings of this study also suggest a relative influential role of humor and jokes on recall ability and reading comprehension and the implications might be for teachers to include humor and jokes in the reading texts that they provide for students.
\end{abstract}

Index Terms—humor, jokes, recall, comprehension, EFL

\section{INTRODUCTION}

Humor is a unique, though universal part of human experience and is fundamentally manifested and expressed through language. It is prevalent in all languages and cultures. Therefore, the employment of humor within the context of second language learning offers great advantages to both language teacher and learner.

However, Second Language Acquisition (SLA) researchers have been very slow to investigate and recognize the great potentials of humor within the language classroom. In recent decades, some studies and surveys have been carried out on the pedagogical effects (both affective and cognitive) of humor whose results show a considerable positive shift of view toward the application of humor in language classroom. Results from a survey by White (2001) show that both teachers and students believe that humor should be used to relieve stress, gain attention, and create a healthy learning environment. Supporting the positive effect of humor on language learning, Schmitz (2002) holds that presentation and study of humor should be an important, integrated part of foreign language classes. He adds that using humor in language courses, in addition to making class more enjoyable, can contribute to improving students' proficiency. He considers humor to be useful for the development of listening comprehension and reading (p. 95).

In addition to fulfilling the aforementioned functions, humor seems to support good memory performance and is believed to have a positive effect on recall of information (Desberg, Henschel, and Marshall 1981; Garner 2006; Schmidt 1994; Schmidt and Williams 2001; Worthen and Deschamps 2008).

\section{STATEMENT OF THE PROBLEM}

One frequently seen problem in most reading classes is hat students encounter the reading text without knowing what it is about beforehand and most often they do not have the interest and motivation to go through the reading passage. Without the necessary interest and motivation, they do not give their full attention to the reading task and subsequently show weak memory storage of the reading passage.

\section{RESEARCH QUESTIONS AND HYPOTHESES}

The current study aims at seeking answers to the following questions:

1. Is there any significant relationship between recall ability and using English jokes as a pre-reading activity? 
2. Are there any significant differences between recall ability of males and females in reading humor related comprehension texts?

The above questions lead to the following hypotheses:

1. There is a positive relationship between recall ability and using English jokes as a pre-reading activity.

2. There are no significant differences between recall ability of males and females in reading humor-based comprehension texts.

\section{REVIEW OF LITERATURE}

\section{A. Humor and Memory}

Humor and fun are intrinsically motivating and arouse and maintain interest during the lesson (Martin 2006, 354; Medgyes 2002, 5; Shade 1996, 97; Tamblyn 2003, 38). Tamblyn (2003), introducing humor as a mnemonic device, explains that humor entertains learners and this entertainment develops intrinsic motivation which is essentially what is called personal relevancy. In clarifying the role of humor in presenting information visually, he believes that everyone remembers pictures far better than words or thoughts (p. 143). Humor and more specifically jokes qualify as visuals; for a joke to be funny, one has to get a mental picture of it (p. 147). Supporting the same idea, Schmidt and Williams (2001), in their study, provided strong evidence for the mnemonic benefit of humor. They believe that the positive effect of humor on recall maybe that humorous material leads to sustained attention and subsequent elaborative processes. They further emphasize that this sustained attention is not simply verbal rehearsal, nor does it require an intention to learn material (p. 311).

\section{B. Humor and Reading Comprehension}

There are some studies which have reported the positive role of using humor in reading classes (Klasky 1979; Shaughnessy and Stanely 1991). Klasky (1979) identifies the reluctancy of readers as a challenge in reading classes and knows humor as the solution to this challenge (p.731). Holding similar idea, Shaughness and Stanely (1991) recognize laughter and humor and the power to play as a way to get students to read and make them take pleasure of their reading (p.4). Based on these pieces of evidence, it is apparent that humor influences the reading classes and reading task by motivating students, providing pleasure and interest for them. Since motivation and attitude towards reading determined a successful reader (Naceur and Schiefel 2005, 167). Some researchers have recommended the insertion of humorous materials into reading classes to motivate and make students interested (Medgyes 2002; Shaughness and Stanely 1991). The results of a survey showed that among the books on and the reading materials selected by students, the categories of humor and horror were among the most attractive, interesting and preferred (Higginbotham 1999).

\section{Memory and Gender}

Regarding the memory performance of the two genders, there are controversial views. While some studies claim that females tend to outperform males on verbal and language tasks (Anderson 2001; Kolb and Wishaw 1990; Lowe, Mayfield and Reynolds 2003). There are some others who either believe that there is no difference between men and women in memory performance (Hyde and Linn in Hyde and Grab 2008, p.156), or that males have larger verbal memory (Geiger \& Litwiller 2005).

\section{Text Comprehension}

The model of text comprehension used in this study is the construction-integration theory proposed by Van Dijk and Kintsch (1983). According to this model, comprehenders process text one chunk (a sentence or clause) at a time. The processing of each chunk consists of extracting and arranging the propositions underlying the message. Then propositions from one part of a text are connected to each other in a network based on overlap of arguments between propositions. In this network, in addition to propositions, inferences, reinstatements, explicit text ideas and generalizations about the gist of situation are connected to each other. All of these elements are connected to each other based on argument overlap. The propositions of a text are represented in long term memory in three levels. The first level is the surface structure which is a mental representation of the exact wording of the text and is forgotten very rapidly. The second level is propositional representation which includes the explicitly stated semantic information in the text and the third level is situation model which is a mental representation of the state of affairs denoted in the text (Van Dijk and Kintsch 1983 in Carroll 2008, p.168).

Comprehension of test probes is like comprehension of a text and the principles of comprehending a text apply to these items too (Singer and Kintsch 2001, 39). Like a text, the test items are also represented in three levels in memory. Based on this, Singer and Kintsch (2001) claim that when a test item is a paraphrase rather than an explicit form, the surface representation link between test probe and text sentence would be absent in memory (p. 39), because the surface form of the remembered sentence is different from that of the test probe. But the propositional and situation links are still there since the meaning of the probe and its role in the situation model is not changed. Now if the test sentence is an inference, both surface link and propositional link would be absent and just the situation link would be retained. Therefore, in case of a paraphrase or an inference, the test sentence is connected only to a portion of the memory representation of the text. The recall and recognition of test probes is influenced by this relationship between text and 
test item. In immediate recall, the acceptance rate for explicit items is considerably higher than for paraphrases and inferences, whereas in delayed recall, the acceptance rate for paraphrases and inferences goes higher. This pattern can be explained with regard to the three levels of propositional representation: in immediate testing, participants still have a detailed representation of surface, text base and situation structure of the text in their memory. Therefore, the explicit items which are consistent with the three levels are accepted the most often, and then are paraphrases which do not match the surface form, but are consistent with text base and situation structure, and finally the least accepted items are inferences that conform only to situation structure. In delayed recall, the exact wording of the message is forgotten and consequently there is a great loss of the content (text base) of the text. Thus, delayed recognition is mostly dependent on situation model.

\section{Methodology}

\section{A. Participants}

Participants of the study were initially 75 male and female English literature and translation students (senior and junior) of Shahid Chamran university of Ahvaz. They ranged in age from 23 to 25. To pull out a group of homogeneous students from this pool, a test of language proficiency was administered. Forty (28 females and 12 males) students whose scores were within a specified range (one standard deviation above and below the mean) were selected to attend the reading sessions.

This selection was done by administering a version of Peterson proficiency test (2005). The reliability of this test computed through KR-21 formula was 0.886. This test consisted of four parts: structure, vocabulary, reading comprehension (which comprised 80 items) and a writing section. The instructions were given orally to students on each part of the test by the researcher. The students were told that: a) They are attending a research; b) They will get negative points for wrong answers; c) The result of the test would not have any effect on the final exam of the course; d) They have 80 minutes time for structure, vocabulary and reading comprehension and one hour for the writing section.

The humorous group comprised the participants who read the reading texts preceded by a joke, and the nonhumorous group consisted of students who studied the same reading text without a joke. The gender of participants was also taken into consideration in the present study.

\section{B. Material}

The texts chosen for this study were 7 reading passages, each about two paragraphs long. The passages were selected from "Intermediate Reading Comprehension" (Mirzaee 1999). The texts were about different general topics such as astronomy, diamond mining, tornado, and life of great men (See appendix for a sample). The texts were selected randomly from the book and to understand them, no specialized knowledge was required. The proficiency level of the texts was intermediate which corresponded to the level of the students. The seven texts were analyzed in terms of propositions and a coherence graph developed using the construction-integration model of Kintsch and Van Dijk (1978; see also Miller and Kintsch 1980). This analysis was done for the purpose of scoring the free writing protocols generated by students during testing session.

The jokes were selected from "English Jokes" (Ghanbari 2004). The selected jokes corresponded to the topics of the reading passages. To avoid possible distractions, the mirths were relevant to academic content (Shade 1996, 47). For every reading passage, one related joke was selected. The selection of texts and jokes were done by the researcher under the supervision of the EFL specialist.

\section{Instruments}

Instruments in this study consist of a proficiency test to produce two homogeneous groups of students in terms of language knowledge, a Likert questionnaire to find seven jokes that seem most funny to students, and seven multiple choice tests and free recall writing papers. The proficiency test was a version of Peterson proficiency test (2005). The reliability of this test computed through KR-21 formula was 0.886 . This test consisted of four parts: structure, vocabulary, reading comprehension (which totally comprised 80 items) and a writing session. The Likert questionnaire consisted of 4 responses. This test was done before students took part in reading sessions and was administered to select the funniest jokes. The responses were

\section{Not funny 2. Little funny $\quad 3$. Funny $\quad$ 4. Very funny}

In order to test the participants' comprehension and thus their recall, seven tests consisting of five multiple choice items were administered. The items were selected from the book "Intermediate Reading Comprehension" (Mirzaee 1999). Since the comprehension tests were selected from the comprehension book, it was assumed that the reliability of tests is counted for by the author.

\section{Procedures}

The two groups attended the reading sessions simultaneously but in different classes. Each reading session took place at the beginning of the class before students went to any other job. The jokes appeared at the beginning of each reading text, one joke being attached to every text. The texts preceded by jokes were given to the humorous group. In each session, one text was studied and it took 20 minutes to read it. The reading sessions were conducted by the researcher. 
Each text was first read aloud by a volunteer to attract everyone's attention and the second time, the students were asked to read it silently. The students could ask the instructor any questions they had about the text. Additionally, they were provided with a glossary of words which were thought may be difficult for them to understand. The glossary was printed on the same page after the reading passage. The texts were taken from participants after they had finished studying them.

The two tasks used in this research to measure the memory performance are question answering and free recall which were performed two days after the reading sessions, i.e. delayed testing. The administration of the two tests like reading the passages was done at the beginning of the session before students got busy and tired by doing other tasks. The two tests were administered in a specific order. The free recall test was given first because if the participants had taken the free recall after the question answering test, they would be able to remember the content of the text and take this information to the free recall test.

In free recall part, students were asked to write whatever they remembered from the reading text on a paper distributed by the instructor. The students were told that it was more important to write as much of the text as they could remember than it was to reproduce the correct grammar and spelling of the original text. The testing phase was repeated seven sessions after each reading session. There was no time limitation in writing the recall protocols and whoever had finished writing was given the question answering paper. Administration of the procedures was done at the presence of the teacher of the class and like any other research project experimenter bias could have occurred.

In the question answering part, students were asked to answer five multiple choice questions regarding the passage they had studied in the previous session. The questions were selected from the same book out of which the reading passages were chosen. So, in sum, there were seven tests of this type, i.e. one test after each reading session.

\section{DATA ANALYSIS}

Data analysis was done based on the construction-integration model mentioned earlier in this paper. To analyze the comprehension and recall of texts by participants, a coherence graph which was the propositional analysis of the texts was drawn for every text. To draw a coherence graph, the following steps were taken: (1) coding the text into propositions, (2) chunking the propositions and (3) connecting the propositions to each other based on argument overlap (propositions that refer to or are referred to by one proposition have an argument overlap with it). To further clarify this process, two sentences of a story analyzed by Singer and Kintsch (2001, p.36) are explained.

S1 we are out of touch with problems which were central in the past. [we, out of touch, problems, central, past]

P1m1 out-of-touch [we, problems]

P1-2 central [problems]

P1-3 time: during [past, problems]

$\mathrm{S} 2$ but this is not true everywhere. [not-true, everywhere]

$\mathrm{P} 2 \mathrm{~m} 2$ not-true [p1m1]

P2-2 everywhere $\{\mathrm{p} 1 \mathrm{~m} 1]$

A. Scoring

The written protocols generated during the delayed recall sessions were scored based on the produced coherence graphs of the texts. A lenient scoring criterion was adopted for scoring students' protocols. Credit was given to meaning that preserved gist or paraphrase as well as to exact meaning preservation or verbatim recall. The lenient scoring criteria also allowed scoring of reinstatements and inferences that were produced in written recalls. Then, the number of propositions in the written protocols produced by students, including all forms mentioned above was counted and divided by the number of propositions of the text and a score was obtained. Scoring was done by use of the coherence graphs already drawn. As mentioned earlier, the coherence graphs were drawn for both reading texts and for the free recall writings of all the students based on the C-I model. The number of propositions in the free recall protocols and the reading texts was determined by the graphs. All the protocols were scored by the researcher and the obtained scores were calculated out of twenty. To take care of the reliability of scoring the free writing protocols, the inter-rater reliability method was conducted. One week later, the scoring and rating were reconsidered by the researcher.

Scores from the post-testing (both free recall and question answering) were subjected to two matched t-tests and two independent t-tests to determine whether or not there are significant differences between each group's performances in terms of the condition of the text they had read. In each reading, the independent variables were presence and absence of a joke and gender of the participants; while, the dependent variable was memory. The two paired t-tests were done to compare the scores obtained from the first and the last reading of both (humorous and non-humorous group), and to determine if any significance change occurred in their recall and comprehension during the seven sessions reading and testing. The independent-test was done to compare the scores obtained from the seven sessions reading and testing by both groups to assess their performance with regard to the presence and absence of the jokes. The other independent $t-$ test was done to compare scores obtained by males and females of the experimental group to determine any significant differences between males and females in terms of recall performance. This test was performed between the two genders of the experimental group because the purpose of the study was to investigate the recall of the two genders with regard to the presence of the joke. 


\section{RESUltS}

In order to find out whether jokes as a pre-reading activity have a positive effect on recall ability of language learners, two different forms of tests were performed: a multiple choice question test and a free recall writing test. The tests were repeated during the seven sessions. The scores obtained from the two types of tests were fed into SPSS and the following results were produced.

Hypothesis one: There is no difference between the recall performance of students who read a joke as a kind of prereading activity with those who do not read a joke beforehand.

Regarding the recall performance of humorous group, results of the matched t-test comparing the scores obtained from the first and the last reading text revealed a significant difference between the comprehension and recall of the first reading text and the last one; $(\mathrm{P}=.021, \mathrm{p}<.05)$ This result shows an increasing trend in recall and comprehension of the seven texts by students of the humorous group (see Table 1).

TABLE 1 .

MATCHED T-TEST COMPARING READINGS OF EXPERIMENTAL GROUP

\begin{tabular}{|c|c|c|c|c|c|c|c|c|}
\hline & \multicolumn{5}{|c|}{ Paired Differences } & \multirow[b]{3}{*}{$\mathrm{T}$} & \multirow[b]{3}{*}{ df } & \multirow{3}{*}{$\begin{array}{l}\text { Sig. }(2 \\
\text { tailed) }\end{array}$} \\
\hline & \multirow[b]{2}{*}{ Mean } & \multirow[b]{2}{*}{ Std. Deviation } & \multirow[b]{2}{*}{ Std. Error Mean } & \multicolumn{2}{|c|}{$\begin{array}{l}95 \% \text { Confidence Interval } \\
\text { of the Difference }\end{array}$} & & & \\
\hline & & & & Lower & Upper & & & \\
\hline Pair 1 VAR00001 - VAR00002 & -4.42188 & 6.88702 & 1.72175 & -8.09171 & -.75204 & -2.568 & 15 & .021 \\
\hline
\end{tabular}

The results of paired t-test obtained from the comparison of the recall of the first and the last reading texts by students of non-humorous group revealed no significant difference between the recall and comprehension of the two reading texts $(\mathrm{P}=.832, \mathrm{p}<.05)$. The result shows that no improvement occurred in the recall and comprehension of the students of the non-humorous group during the seven reading sessions (Table 2).

TABLE 2.

PAIRED T-TEST COMPARING READINGS OF CONTROL

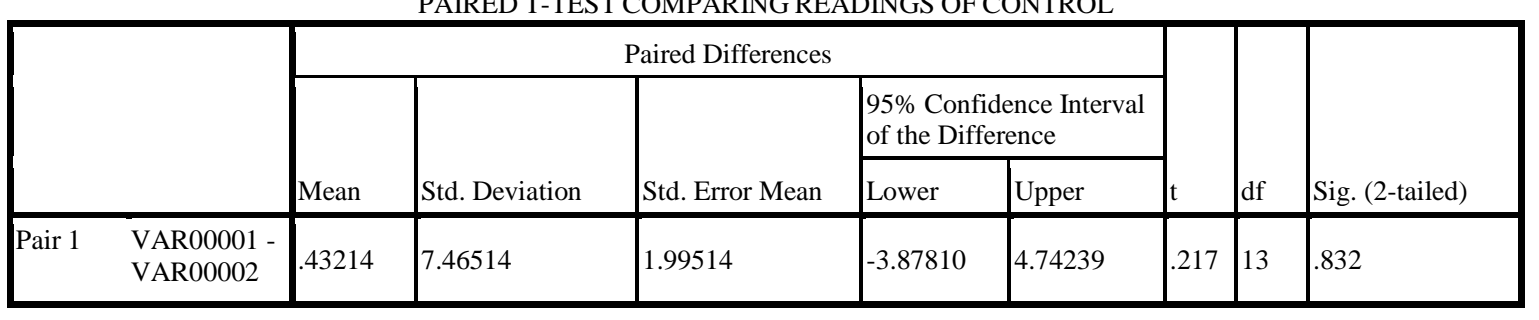

Analysis of the scores obtained from the independent t-test which compared the recall of students of the humorous group with the students of the non-humorous group revealed no significant difference by recall condition between the recall and comprehension of the two groups regarding reading the seven texts $(\mathrm{P}=.905, \mathrm{p}>.05)$. Table 3 displays the statistical findings obtained as a result of comparison.

TABLE 3.

INDEPENDENT T-TEST COMPARING THE RECALL OF STUDENTS IN HUMOROUS AND NON-HUMOROUS GROUPS

\begin{tabular}{|c|c|c|c|c|c|c|c|c|c|c|}
\hline & & \multicolumn{2}{|c|}{$\begin{array}{l}\text { Levene's Test for } \\
\text { Equality of Variances }\end{array}$} & \multicolumn{7}{|c|}{ t-test for Equality of Means } \\
\hline & & \multirow[b]{2}{*}{$\mathrm{F}$} & \multirow[b]{2}{*}{ Sig. } & \multirow[b]{2}{*}{$\mathrm{t}$} & \multirow[b]{2}{*}{ df } & \multirow{2}{*}{$\begin{array}{l}\text { Sig. (2- } \\
\text { tailed) }\end{array}$} & \multirow{2}{*}{$\begin{array}{l}\text { Mean } \\
\text { Difference }\end{array}$} & \multirow{2}{*}{$\begin{array}{l}\text { Std. Error } \\
\text { Difference }\end{array}$} & \multicolumn{2}{|c|}{$\begin{array}{l}\text { 95\% Confidence Interval of } \\
\text { the Difference }\end{array}$} \\
\hline & & & & & & & & & Lower & Upper \\
\hline VAR00001 & $\begin{array}{l}\text { Equal variances } \\
\text { assumed } \\
\text { Equal variances } \\
\text { not assumed }\end{array}$ & 8.307 & .004 & $\begin{array}{l}.119 \\
.119\end{array}$ & $\begin{array}{l}250 \\
235.848\end{array}$ & $\begin{array}{l}.905 \\
.905\end{array}$ & $\begin{array}{l}.10135 \\
.10135\end{array}$ & $\begin{array}{l}.85240 \\
.85240\end{array}$ & $\begin{array}{l}-1.57745 \\
-1.57794\end{array}$ & $\begin{array}{l}1.78014 \\
1.78063\end{array}$ \\
\hline
\end{tabular}

Hypothesis two: There is no difference between males' and females' recall ability in reading a humor related text.

Finally, the results of the independent t-test which compared the scores obtained from the recall tests of males and females of the experimental group revealed a significant difference between the recall and comprehension of the two genders $(\mathrm{P}=.009, \mathrm{p}<.01)$. As revealed in tables 4 and 5 , comparing the means of the scores obtained by the two genders shows the outperformance of the males over the females. 
TABLE 4.

INDEPENDENT T-TEST COMPARING MALE AND FEMALE PERFORMANCES

\begin{tabular}{|c|c|c|c|c|c|c|c|c|c|c|}
\hline & & \multicolumn{2}{|c|}{ Levene Test ... } & \multicolumn{7}{|c|}{ t-test for Equality... } \\
\hline & & \multirow[b]{2}{*}{$\mathrm{F}$} & \multirow[b]{2}{*}{ Significance } & \multirow[b]{2}{*}{$\mathrm{t}$} & \multirow[b]{2}{*}{ Df } & \multirow{2}{*}{$\begin{array}{l}\operatorname{Sig}(2- \\
\text { tailed }) \ldots\end{array}$} & \multirow{2}{*}{$\begin{array}{l}\text { Mean } \\
\text { Difference }\end{array}$} & \multirow{2}{*}{\begin{tabular}{|l} 
Std. Error \\
Diff...
\end{tabular}} & \multicolumn{2}{|c|}{$\begin{array}{l}\text { 95\% Confidence Interval of } \\
\text { the Difference }\end{array}$} \\
\hline & & & & & & & & & Lower & Upper \\
\hline VAR00001 & $\begin{array}{l}\text { Equal variances ... } \\
\text { Not Equal } \\
\text { variances ... }\end{array}$ & .002 & .966 & $\begin{array}{l}-2.663 \\
-2.618\end{array}$ & $\begin{array}{l}122 \\
70.924\end{array}$ & $\begin{array}{l}.009 \\
.011\end{array}$ & $\begin{array}{l}-3.59627 \\
-3.59627\end{array}$ & $\begin{array}{l}1.35064 \\
1.37345\end{array}$ & $\begin{array}{l}-6.27000 \\
-6.33489\end{array}$ & $\begin{array}{l}-.92253 \\
-.85764\end{array}$ \\
\hline
\end{tabular}

TABLE 5

\begin{tabular}{|ll|l|l|l|l|}
\hline & VAR00002 & $\mathrm{N}$ & Mean & Std. Deviation & Std. Error Mean \\
\hline VAR00001 & 0 & 85 & 20.5768 & 6.88375 & .74665 \\
& male & 39 & 24.1731 & 7.19904 & 1.15277 \\
\hline
\end{tabular}

In light of the above-mentioned results, hypothesis 1 is accepted, but the second hypothesis is rejected since males showed a relatively better performance in their recall and comprehension over females.

\section{DISCUSSION}

The results of the present study revealed improvement in the recall and comprehension of the texts by participants of the humorous group across the seven sessions reading and testing. The scores obtained during the seven sessions of reading and testing revealed no significant difference in recall and comprehension of the two groups. Finally, the results of comparing the scores of males and females of the humorous group showed a relatively better performance of males compared to females. These results will be interpreted in the light of the cognitive and affective processes involved in comprehension.

It appears that the improvement in recall and comprehension of the humorous group over the first and the last reading sessions is related to the presence of the joke before the reading text. One logical explanation for the effect of joke on the better performance of the humorous group compared to the non-humorous group is that reading the joke produces an inner motivation and interest in reader, so the reader goes through reading the text with greater enthusiasm and thus pays closer attention to the content and this "close attention leads to more accurate and more complete remembering" (Reisberg 2006, 23). The attention generated by individual interest functions like a filter and lets the material which is interesting and focused by the reader in the mind and disregards any other irrelevant thought that can interfere with processing the reading text. Thus, reading the joke provokes an interest in the participants of humorous group. The produced interest takes away students' attention from any peripheral and interfering thought and focuses their attention toward reading the text and recognizing and processing its main points. Just as Berk (2002, p.5) points out, humor functions as a "hook" to attract and maintain student's attention. By "hook", Berk means activities or experiences which engage the emotion and mind of students, pulls them into the learning process, and prevent their thoughts from wandering around. Berk believes that humor provides such activities and experiences to focus students' attention especially in long lasting and boring classes.

Bearing in mind that, on the one hand, humor triggers interest and produces intrinsic motivation in individuals (Martin 2006, 354; Medgyes 2002, p.5; Shade 1996, p.97; Tamblyn 2003, p.38), and that the intrinsic motivation deeply engages people in doing the task (Renninger 2000, 38), and, on the other hand, motivation is a key factor in comprehension of a text (Guthrie and Scafiddi 2004, 277), it can be claimed that the improvement in recall and comprehension of participants of the humorous group is due to their increased interest and motivation. Renninger (2000, p.379) states that, "for an individual interest to continue to develop, a person needs opportunities for cognitive challenge". It was already argued that, to comprehend humor, one should be able to solve the incongruity involved with it and resolving the incongruity imposes a cognitive challenge on the mind of the reader. Based on this, it can be said that as the participants of the humorous group continue reading the passages during the seven sessions, reading every joke at the beginning of the passage challenges their cognition and consequently their interest continues to develop over the seven sessions. Individual interest, in addition to, fulfilling the above mentioned functions is an effective factor in attracting the person's attention. As such, it functions like a filter for information to which a person pays attention (Renninger 2000, p.380).

Attention influences memory performance by affecting both working memory and long term memory. Attention is necessary to hold information in working memory and to move information to long-term memory more efficiently (Wickens and Mccarley 2008, 1). The ability to focus attention correlates with working memory capacity. Individuals with good attention control skills, and will better be able to maintain the information stored in short term buffers (Wickens and Mccarley 2008, p.170).

To describe how attention affects recall, it is necessary first to introduce the notion of "priming". Priming is defined as a "nonconscious or implicit form of memory" (Stevens, Wig and Schacter 2008, 66). Increased attention at the time 
of study seems to be an important factor in priming. Results of some studies reported by Stevens, and others indicated that top down effects of attention can have an impact on priming, both at the time of study and test and have been shown to involve both spatial attention and task relevant selective attention.

Another plausible explanation for observed improvement is, since the joke is identical in content to the reading passage, it plays as an activator of the related schemata and activates the content schemata of the learners and make them prepared for reading the text material. A content schema is the knowledge about people, the world, culture and the universe. Another possible explanation for the observed outperformance of humorous group over the non-humorous group regarding the first and the last reading text is the functioning of joke as a mnemonic device. In this regard, Millis and King (2001, p.42) believe that the use of mnemonic devices while reading a text helps memory performance. The joke which appears at the beginning of the reading text entertains the readers. This entertainment leads to higher intrinsic motivation and this motivation is called personal relevancy (Tamblyn 2003, p.143). Another function of jokes as a mnemonic device is its role in provocation of sustained attention and the subsequent elaborative processes which lead to better storage and recall (Schmidt and Williams 2001, p.311).

Looking at humor from the emotional side, it was already mentioned that reading and comprehending humor engages emotion (Martin 2006, p.7), and emotion makes remembering the material more accurate and long lasting (Reisberg 2006, p.17). Putting these two comments together, the logical conclusion is that the participants of humorous group showed a better recall performance because reading the joke at the beginning of the reading text arouses their emotion and thus leads to better remembering.

Results of the independent t-test which compared the recall performance of males and females of humorous group revealed that males outperform females in recall ability. This outperformance can be explained in terms of the presence of the joke which improves brain's performance on spatial temporal reasoning tasks (Berk 2001, p.7) and the superiority of males over females in spatial memory (Anderson 2001; Geiger and Litwiller 2005; Kolb and Wishaw 1990; Lowe, Mayfield, and Reynolds 2003) leading to the better performance of males. Spatial memory is one dimension of the situational representation of a text in cognition and has a powerful effect on the reader's memory (Zwaan and Singer 2008, p.93). Zwaan and Singer (2008) further state that "the spatial representations are not detailed unless the reader is instructed, constrained, or intrinsically motivated to construct a detailed spatial representation" (p.94). Based on this, it can be claimed that the presence of the joke has motivated the readers to build a detailed spatial representation and because males perform better on spatial tasks, their recall performance is better than their female counterparts.

Findings of the independent t-test that compared the recall performance of the humorous and non-humorous groups across all the seven reading and testing sessions revealed no significant difference between the performances of the two groups. This finding was contrary to the previous studies claiming that humor has a positive effect on recall ability. The observed unexpectedness could be related to the absence of the jokes at the time of testing. This could be explained through the notion of "specificity of priming". Specificity is "the degree to which priming is disrupted by changes between the encoding and test phases of an experiment" (Stevens, Wig and Schacter 2008, p.72). According to this definition, when study or test changes along a specific dimension, it leads to a reduction in priming. The presence of the joke at the time of study and its absence at the time of testing has produced a change which reduces the amount of priming.

Taking into account the pattern of test probes recall, Kintsch and Van Dijk's (1978) prediction about the acceptance rate of the test probes across immediate and delayed recall intervals states that, in immediate recall test, explicit items, paraphrased items, and the inferences are accepted respectively. With increased delay, this pattern changes and the acceptance rate goes higher toward inferences and then paraphrased items and the least accepted are explicit items. Analyzing the test probes of the present study which were totally 35 items revealed that 40 percent of the probes were explicit (the exact wording of the text was set as the probe), 40 percent were paraphrased items (the test probe was a rewording of ideas expressed in the text), and 20 percent were inferences (the probe asked students about a deduction they had to draw from reading the text). This categorization was done by use of both inter-rater and intra-rater scoring. The analysis of the probes was not consistent with the Kintsch and Van Dijk's prediction. The percentage of correct answers given to explicit items was the highest $(86.5 \%)$; next were the paraphrased items $(61 \%)$ and the least recognized items were inferences (49\%). This inconsistency may have to do with the limited number of post testing sessions which was one single delayed post testing session, while, the pattern of probe test recall proposed by Kintsch and Van dijk (1978) was drawn by data obtained from immediate and several delayed post testing. They repeated the test 4 times: the first test was performed immediately after reading the text; the second test was done 20 minutes later; the third one was performed 40 minutes and the last one was performed 2 days later while the testing procedure in the present study took place only once and it was 2 days after the reading sessions.

Distinguishing between statements generated in free recall test, Kintsch and Van Dijk classify them into reproductions and reconstructions. Reproductions are "responses which correspond to propositions expressed directly in the original article" and reconstructions are "sensible guesses but do not have counterpart propositions in the text" (Kintsch and Van Dijk 1978 in Zwaan and Singer 2008, 111). Kintsch and Van Dijk found that in immediate recall, the responses are more reproductions and with increased delay, they move toward reconstructions. Analysis of the responses produced in the free recall testing of the present study indicated that 60 percent of the responses were 
reconstructions. These results are close to Kintsch and Van Dijk's findings, since with 2 days delay between readings and testing which was a relatively long one, the statements were expected to move toward reconstructions.

\section{LIMITATIONS OF THE STUDY}

This study was subject to a number of limitations. The first one was associated with the restricted number of reading sessions. In the case of this study, more passages and more reading sessions would have been preferable. Using the existing data obtained from only one single delayed testing session which occurred after each reading session made another restriction. With both delayed and immediate testing, the obtained results would have been more reliable and would produce more comprehensive interpretations. Another potential limitation may involve the way we assessed the homogeneity of the participants. To carry out this research study, students participated in a general proficiency test based on which they were divided into two homogeneous groups. There existed other variables like short memory span which could not be measured by a proficiency test. Short term memory is one of the factors which affect comprehension and recall of a text (Carroll 2008, 162). While this study examined the effect of jokes on recall performance by arguing that jokes may affect recall because they produce interest and motivation in the reader, it did not measure the topic interest of reading passages which could have affected the recall of the texts by students of both groups.

\section{CONCLUSIONS AND PEDAGOGICAL IMPLICATIONS}

The present study was based on our belief that it is necessary to investigate the relations between humor (English jokes), recall ability and reading comprehension in more details. It is not enough to look at the positive effect of humor on recalling some isolated words or sentences without considering a specific context or a language skill. However, when we want to learn more about processes and mechanisms that may help to explain the effects of humor on recall and comprehension of texts then it is essential to use specific memory measures and to examine memory and comprehension processes in a specific situation, and to choose a definite subcategory of humor.

In the present study, we chose a specific text learning situation and a specific category of humor, namely, joke. The major goals were to test whether recall ability and reading comprehension are affected by the presence of a humorous element (joke) in the reading texts and whether males and females show a different performance in recalling humorous texts.

The findings with respect to the t-test which compared the scores of recall tests of both groups over the seven sessions revealed no significant difference between the recall performances of the two groups. However, comparing the scores obtained from the first and the last reading by humorous group showed a significant improvement in the recall and comprehension of the experimental group.

The findings of this study suggest a relative influential role of humor and jokes on recall ability and reading comprehension and the implications might be for teachers to include humor and jokes in the reading texts that they provide for students. By so doing, teachers can motivate students and attract their attention toward reading the text. In this case, jokes coming before the main reading passage can function as a pre-reading activity. In addition, these findings might help curriculum developers and material designers to provide materials which include some humorous elements.

\section{APPENDIX}

A sample text used in the study:

Clerk in post office, after weighing letter: "that letter is too heavy".

"You'll have to put another stamp on it".

Man: "what is the good of that? If I put another stamp on it, that will make it still heavier, won't it?"

How can a single postage stamp be worth $\$ 16,800$ ?

Any mistake made in the printing of a stamp raises its value to stamp collectors. A mistake on one inexpensive postage stamp has made the stamp worth a million and a half times its original value. The mistake was made more than a hundred years ago in the British colony of Mauritius, a small island in the Indian Ocean. In 1847 an order for stamps was sent to a London printer- Mauritius was to become the fourth country in the world to issue stamps. Before the order was filled and delivered, a ball was planned at Mauritius' government house, and stamps were needed to send out the invitations. A local printer was instructed to copy the design for the stamps. He accidentally inscribed the words "post office" instead of "post paid" on the several hundred stamps that he printed.

since the reading scores of males and females of this study were obtained from 7 sessions reading and testing, so the number of males and females is multiplied by the number of testing sessions and hence the numbers 85 and 39 in (table 5) is the result of this estimation.

\section{REFERENCES}

[1] Anderson, J. (2001). Net effect of memory collaboration: how is collaboration affected by factors such as friendship, gender and age? Scandinavian Journal of Psychology, 42, 367-375. 
[2] Berk, R. A. (2002). Humor as an instructional defibrillator. Virginia: Stylus Publishing.

[3] Carroll, D. W. (2008). Psychology of language. Canada: Wadsworth publishing.

[4] Desberg, P., Henschel, D., \& Marshall, C. (1981). The effect of humor on retention of lecture material. Paper presented at the 1981 American Psychology association convention. Retrieved from the World Wide Web http://eric.ed.gov/ ERICDOCS/data/ ericdocs2q1/content_storage.

[5] Garner, R. L. (2006). Humor in pedagogy. How ha-ha can lead to aha. College Teaching, 54(1), 177-180.

[6] Geiger, J. F., \& Litwiller, R. M. (2005). Spatial working memory and gender differences in science. Journal of Instructional Psychology, 32(1), 49-57.

[7] Ghanbari, A. (2004). English jokes. Tehran: Rahnama publications.

[8] Guthrie, J.T., \& scafiddi, N.T. (2004). Reading comprehension for information text: Theoretical meanings, Developmental patterns, and benchmarks for instruction. In Guthrie, J.T, Wigfield, A. \& Perencevich, K.C (Eds). Motivating reading comprehension. (pp. 225-249). London: Lawrence Erlbaum associates.

[9] Higginbotham, S. (1999). Reading interests of middle school students and reading preferences by gender of middle school students in a southeastern state. Master's Thesis Disseratations. Mercer University.

[10] Hyde, J.Sh., \& Grabe, Sh. (2008). Meta-analysis in psychology of women. In Denmark, F.L. \& Paludi, M.A (Eds). Psychology of women: a handbook of issues \& theories. (pp. 142-174). London: Praeger.

[11] Kintsch, W., \& Van Dijk, T.A. (1978). Toward a model of text comprehension and production. Psychological Review, 85, 363394.

[12] Klasky, C. (1979). Some funny business in your reading classes. Journal of Reading, 22 (8), 731-733.

[13] Kolb, B., \& Wishaw, I.Q. (1990). Fundamentals of human neuropsychology: fifth edition. New York: W. H. Freeman and Company.

[14] Lowe, A.P., Mayfield, W.J., \& Reynolds, R.C. (2003). Gender differences in memory test Performance among children and adolescents. Journal of Archives of Clinical NeuroPsychology, 18(8), 865-878.

[15] Martin, R.A. (2006). The psychology of humor. New York: Academic Press.

[16] Medgyes, P. (2002). Laughing matters. Cambridge: Cambridge University Press.

[17] Miller, J.E.,\& Kintsch, W. (1980). Recall and readability of short prose passages. Paper presented at the annual meeting of the American educational research association. Retrieved from the World Wide Web http:// eric.ed.gov/ ERICDOCS/ data/ ericdocs2q1/content_storage.

[18] Millis, K. \& King. (2001). Rereading strategically: The influences of comprehension ability and a prior reading on the memory for expository text. Reading Psychology, 22, 41-65.

[19] Mirzaee, M. D. (2005). Intermediate reading comprehension. Tehran: Rahnama publications.

[20] Naceur, A.,\& Schiefele, U. (2005). Motivational and learning - the role of interest in construction of representation of text and long - term retention: inter - and intraindividual analyses. European Journal of Psychology of Education, 20 (2), 155-170.

[21] Peterson's, T. (2005).peterson's TOEFL success. New Jersey: heinle \& heinle/ thamson learning.

[22] Reisberg, D. (2006). Memory for emotional episodes: the strengths and limits of arousal based accounts. In B. Uttl, N. Ohta \& A. L. Siegenthaler (Eds.), Memory and emotion, (pp. 15-37). Oxford: Blackwell Publishing.

[23] Renninger, K. A. (2000). Individual interest and its implications for understanding intrinsic motivation. In C. Sansone \& J. M. Harackiewicz (Eds), Intrinsic and Extrinsic motivation: The search for optimal motivation and performance (pp. 373-404). San Diego, CA: Academic Press.

[24] Shade, R. A. (1996). License to laugh: Humor in the classroom. Colorado: Teacher Ideas Press.

[25] Schmitz, J.R. (2002). Humor as a pedagogical tool in foreign language and translation classes. International Journal of humor research, 15(1), 89-113.

[26] Schmidt, S.R., \& Williams, A.L. (2001). Memory for humorous cartoons. Memory and Cognition, 29 (2), 305-311.

[27] Shughnessy, M. F., \& Stanely, N. V. (1991). Teaching reading through humor. Retrieved from the World Wide Web http:/ eric.ed.gov/ (ERIC documents reproduction service No. ED332152).

[28] Singer, M. \& Kintsch, W. (2001). Text retrieval: a theoretical exploration. Discourse processes, 31(1), $27-59$.

[29] Stevens, W.D., Wig, G.S, \& Schacter, D.L. (2008). Implicit memory and priming In J.H. Byrne (ed.), Concise learning and memory, (pp. 65-86). London: Academic Press.

[30] Tamblyn, T. (2003). 95 ways to use humor for more effective teaching and training. New York: American Management Association.

[31] Van Dijk, T.A \&. Kintsch, W. (1983). Strategies of discourse comprehension. New York: Academic Press.

[32] White, G.W. (2001). Teachers' report of how they used humor with students perceived use of such humor. Education, 122 (2), 337-347.

[33] Wickens, C.D., \& Mccarley, J.S. (2008). Applied attention theory. New York: Talor \& Francis group.

[34] Worthen, J.B., \& Deschamps, J.D. (2008). Humor mediates the facilitative effect of bizarreness in delayed recall. British journal of psychology, 99, 461-471.

[35] Zwaan, R.A., \& Singer, M. (2008). Text comprehension. In A.C. Graesser, M.A. Gernsbacher \& S.R. Goldman (Eds), Handbook of Discourse Processes, (pp. 83-117). London: Lawrence Erlbaum Associates.

A. Majid Hayati, an Associate Professor of Linguistics, holds a doctorate degree in Linguistics from the University of Newcastle, Australia. He teaches TEFL, Language Testing, Linguistics, Contrastive Analysis, etc. at Shahid Chamran University of Ahvaz. Hayati has published a number of articles in Roshd Magazine (Iran), Reading Matrix (USA), PSiCL (Poland), Asian EFL Journal (Korea), Arts and Humanities in Higher Education (England), ELT (Canada), etc. He has also published the second edition of his book "Contrastive Analysis: Theory and Practice" in 2005. He was accepted as the outstanding researcher by the International Biographical Center (IBC) as a result of which his biography was included in the following titles: Outstanding People of the 20th 
Century- Second Edition; 2000 Outstanding Scholars of the 20th Century, First Edition; Outstanding People of the 21st Century First Edition.

Zohreh Gooniband Shooshtari, an Assistant Professor of English, holds a doctorate degree in Applied Linguistics from the University of Isfahan, Iran. She teaches different courses such as Issues in Linguistics, Teaching Methodology, Testing, Language Skills, etc. at Shahid Chamran University of Ahvaz. She has published a number of articles in different local and international journals.

Nahid Shakeri, holds an MA in TEFL from Shahid Chamran University of Ahvaz. She is currently an instructor of English in Kerman. Her special field of interest includes Language Teaching, Applied Linguistics, and English for Specific Purposes. 